\title{
(6) OPEN ACCESS \\ Sidecut radius and the mechanics of turning- equipment designed to reduce risk of severe traumatic knee injuries in alpine giant slalom ski racing
}

\author{
Jörg Spörri, ${ }^{1}$ Josef Kröll, ${ }^{1}$ Matthias Gilgien, ${ }^{2}$ Erich Müller ${ }^{1}$
}

'Department of Sport Science and Kinesiology, University of Salzburg, Hallein-Rif, Austria ${ }^{2}$ Department of Physical Performance, Norwegian School of Sport Sciences, Oslo, Norway

\section{Correspondence to}

Dr Jörg Spörri, Department of Sport Science and Kinesiology, University of Salzburg, Schlossallee 49, Hallein-Rif 5400, Austria; joerg.spoerri@sbg.ac.at

Accepted 6 November 2015

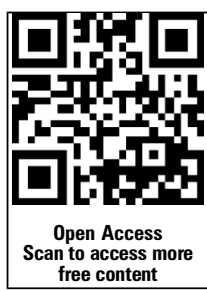

CrossMark

To cite: Spörri J, Kröll J, Gilgien $\mathrm{M}$, et al. Br J Sports Med 2016;50:14-19.
ABSTRACT

Background There is limited empirical knowledge about the effect of ski geometry, particularly in the context of injury prevention in alpine ski racing. We investigated the effect of sidecut radius on

biomechanical variables related to the mechanics of turning.

Methods During a field experiment, six European Cup level athletes skied on three different pairs of giant slalom (GS) skis varying in sidecut radii $(30 \mathrm{~m}, 35 \mathrm{~m}$ and $40 \mathrm{~m}$ ). Using a video-based three-dimensional (3D) kinematic system, a 22-point body segment model of the athletes was reconstructed in $3 \mathrm{D}$, and the variables ground reaction force, centre of mass (COM) speed, COM turn radius, ski turn radius, edge angle, fore/aft position and skid angle were calculated.

Results While steering out of the fall line after gate passage, ground reaction force significantly differed between the $30 \mathrm{~m}$ and $40 \mathrm{~m}$ skis and between the $35 \mathrm{~m}$ and $40 \mathrm{~m}$ skis. These differences were mainly explainable by larger COM turn radii when skiing on the $40 \mathrm{~m}$ ski. During the same turn phase, significant differences in ski turn radius also were found, but there were no differences in edge angle, fore/aft position and skid angle.

Summary The sidecut-induced reduction in ground reaction force and the sidecut-induced increase in centre of mass and ski turn radius observed in this study provides indirect evidence of reduced self-steering of the ski. Self-steering plays a central role in the mechanism of anterior cruciate ligament rupture in alpine ski racing.

\section{INTRODUCTION}

In alpine ski racing, the risk of sustaining a severe knee injury is known to be high. ${ }^{1-4}$ The absolute rate of knee injuries in World Cup (WC) alpine skiers has been reported to be 13.8 injuries/100 athletes/season. ${ }^{3}$ Recent studies have provided a deeper understanding of the underlying injury mechanisms. ${ }^{5}{ }^{6}$ Most anterior cruciate ligament (ACL) injuries occur while skiing without the athlete crashing. ${ }^{5}$ More than half of all ACL injuries were ascribed to the so called 'slip-catch' mechanism while turning. ${ }^{5} \mathrm{~A}$ common characteristic of this injury mechanism is that, initially, the skier loses balance backward and inward while steering out of the fall line and loses the pressure on the outer ski. ${ }^{5}$ Then, while trying to regain grip on the outer ski, the inside edge of the outer ski abruptly catches the snow surface, suddenly increasing of knee joint compression, knee valgus and internal rotation and, as a result, a rupture of the ACL. ${ }^{6}$ These adverse loading patterns are related to the ski's self-steering effect. ${ }^{5-7}$

The ski's self-steering effect (ie, the ski turns itself if it is edged and loaded) is theoretically expected to depend on its sidecut radius and its longitudinal and torsional stiffness. ${ }^{8}$ Basically, a ski with a small sidecut radius enables the skier to carve tight turns with a minimum of skidding, as long as the ski is loaded and under control. ${ }^{9-11}$ However, in an uncontrolled skiing situation (eg, a sudden catch of the edge while recovering from an out-of-balance situation), the skier's centre of mass (COM) cannot follow the path of the ski anymore; because of the small sidecut radius, the ski will carve inward sharply and force the knee into excessive valgus and internal rotation. ${ }^{6}$

While the influence of the ski's sidecut radius during the injury mechanism itself is readily apparent ${ }^{5-7}$ its effect on the general mechanics of turning is still not well understood. Theoretical models and parameter studies have provided valuable insights into the basic mechanics of turning, and revealed important general knowledge about the effect of equipment properties. ${ }^{12-22}$ However, as all of these approaches neglect some of the skiers' adaption mechanisms (eg, adjustments of the amount of skidding), it is not clear how sidecut radius influences the relation between turn speed and turn radius, and the resultant ground reaction force under realistic in-field conditions. This knowledge is essential to clarify the role of sidecut radius as a cause of ACL injuries in alpine ski racing, particularly as more than half of these injuries occur while turning. ${ }^{5}$

Therefore, we: (1) investigated the effect of skis with different sidecut radii on variables related to the mechanics of turning in giant slalom (GS); and (2) discuss the findings in the context of injury prevention in alpine ski racing.

\section{METHODS}

\section{Measurement protocol and data collection}

During a biomechanical field experiment, six European Cup level athletes skied GS runs on three different pairs of skis with varying sidecut radii $(30 \mathrm{~m}, 35 \mathrm{~m}$ and $40 \mathrm{~m})$. All other geometrical specifications of the skis were in accordance with the current equipment rules of the International Ski Federation (FIS). ${ }^{23}$ In order to become accustomed to the different skis, in the months prior the experiment, the athletes skied them during 
their regular training sessions. The GS course was set on a $26^{\circ}$ inclined, water-injected slope with an average gate distance of $27 \mathrm{~m}$ and an offset of $8 \mathrm{~m}$ (figure 1). In the mid-section of the course, the athletes were simultaneously filmed over one turn cycle by six panned, tilted and zoomed HDV-cameras (Sony PMW-EX3, $50 \mathrm{~Hz}$, gen-locked). A total of 142 reference points were positioned around the analysed turn and were geodetically measured by a tachymeter (Leica Total station 1200). For each of the analysed turns, a 22-point body segment model and subject ambient reference points were manually digitised in each frame of each camera. Finally, a direct linear transformation (DLT)-based panning algorithm by Drenk ${ }^{24}$ and the position information of the geodetic measured reference points were used to reconstruct a segment model of each skier in three-dimensional (3D). Manual digitising and model reconstruction were performed using a custom-made software (Volker Drenk, Germany). Owing to reasons of processing time manageability, for each of the six athletes and three pairs of skis, only the fastest run out of three (ie, the run with shortest section time between gates 1 and 5 as illustrated in figure 1) was considered for the data analysis, resulting in a total of 18 analysed turns. The measurement method used has been shown to be reliable for collecting kinematic data under in-field conditions in an earlier study with comparable setup and circumstances. $^{25}$

\section{Postprocessing and calculations}

Postprocessing and calculations were performed in MATLAB, $R 2012 b$. The reconstructed $3 \mathrm{D}$ position data of each landmark was low-pass filtered using a second-order Butterworth filter with a cut-off frequency between 2 and $5 \mathrm{~Hz}$ determined using the Jackson-Knee method. ${ }^{26}$ In addition, using a technique suggested by Smith, ${ }^{27}$ the reconstructed body segments were normalised based on anthropometrical data that was measured following the protocol of de Leva. ${ }^{28} \mathrm{COM}$ position was calculated based on the model of Clauser et al, ${ }^{29}$ adapted with the skiing equipment as carried out in earlier studies. ${ }^{30} 31$ The beginning and end of the turn were defined as the crossing points of the ski trajectory (=path travelled by the midpoint between the outer and the inner ankle) and the COM-trajectory orthogonally projected to the slope plane, as suggested by Supej et $a .^{32}$ The four functional turn phases Initiation, COM Direction Change I, COM Direction Change II and Completion were defined in accordance to Spörri et al. ${ }^{30}$ Ground reaction force $\left(\mathrm{F}_{\text {calcGRF }}\right)$ was defined in accordance with Mössner et al ${ }^{11}$ as the root of squared total radial force plus squared normal force, and was calculated based on the measured kinematic data, skier's mass and slope inclination angle. Furthermore, the plausibility of the aforementioned method to calculate $F_{\text {calcGRF }}$ was double checked by the use of an alternative kinematic-based computation method introduced by Gilgien et al, ${ }^{33}$ which additionally considers an estimation of air drag and ski snow friction force. COM speed ( $\left.\mathrm{v}_{\mathrm{COM}}\right)$, COM turn radius $\left(\mathrm{R}_{\mathrm{COM}}\right)$, fore/ aft position $\left(\mathrm{d}_{\text {Fore/Aft }}\right)$ and skid angle $\left(\gamma_{\mathrm{Ski}}\right)$ were determined as described in earlier studies. ${ }^{30} 31$ Ski turn radius $\left(\mathrm{R}_{\text {Ski }}\right)$ was calculated in analogy to $\mathrm{R}_{\mathrm{COM}}$ based on the ankle joint trajectory of the outer leg. For the calculation of the edge angle $\left(\theta_{\text {Edge }}\right)$, a local coordinate system (x'y'z') at the ankle joint of the outside ski was used (figure 2). $x$ ' was defined by the joint ankle and the direction of the longitudinal axis of the ski. z' was defined to be perpendicular to the slope plane and y' was defined as forming a right-handed triad with $x^{\prime}$ and $z^{\prime}$. $\theta_{\text {Edge }}$ was then calculated as the angle between the $\mathrm{z}$-axis and the ankle-knee vector projected to the y'-z' plane.

\section{Statistical analysis}

The statistical analysis included the following steps: (1) based on the data of one turn cycle per athlete, the group mean curves (ie, the ensemble averaged individual curves) of $\mathrm{F}_{\text {calcGRF }}$ $\mathrm{v}_{\mathrm{COM}}, \mathrm{R}_{\mathrm{COM}}, \mathrm{R}_{\mathrm{Ski}}, \theta_{\text {Edge }}, \mathrm{d}_{\text {Fore/Aft }}$, $\gamma_{\text {Ski }}$ were calculated for each pair of skis. Thereafter, for each variable the differences between the three different pairs of skis $(30 \mathrm{~m}, 35 \mathrm{~m}$ and $40 \mathrm{~m}$ sidecut radius) were visualised by plotting the areas of uncertainty around the estimate of the mean ( \pm SE boundaries). (2) Ski differences in average $F_{\text {calcGRF }}$ over the entire turn cycle and within the specific turn phases were tested for significance using one-way repeated measures analysis of variance (ANOVA), including post hoc testing with Bonferroni
Figure 1 Schematic on-hill setup (CAM 1-6: positions of the panned, tilted and zoomed video-cameras).

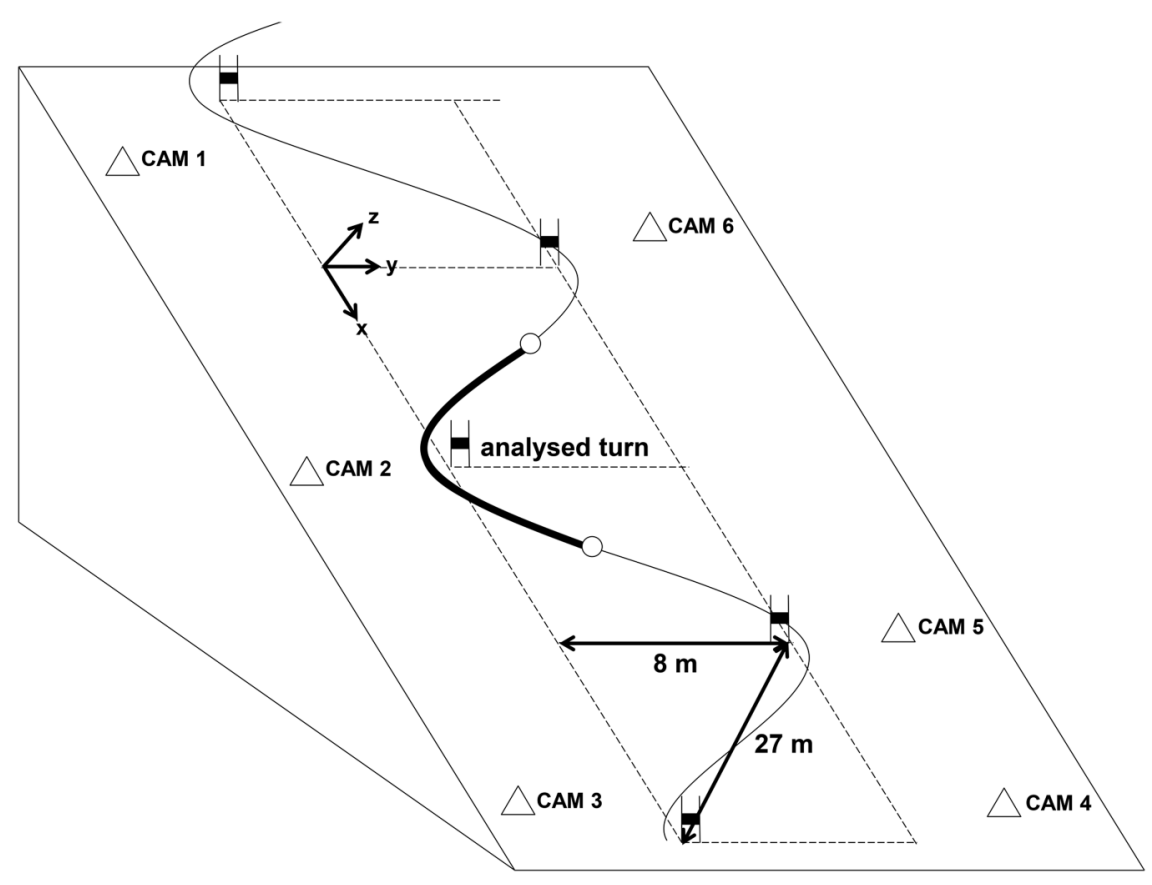



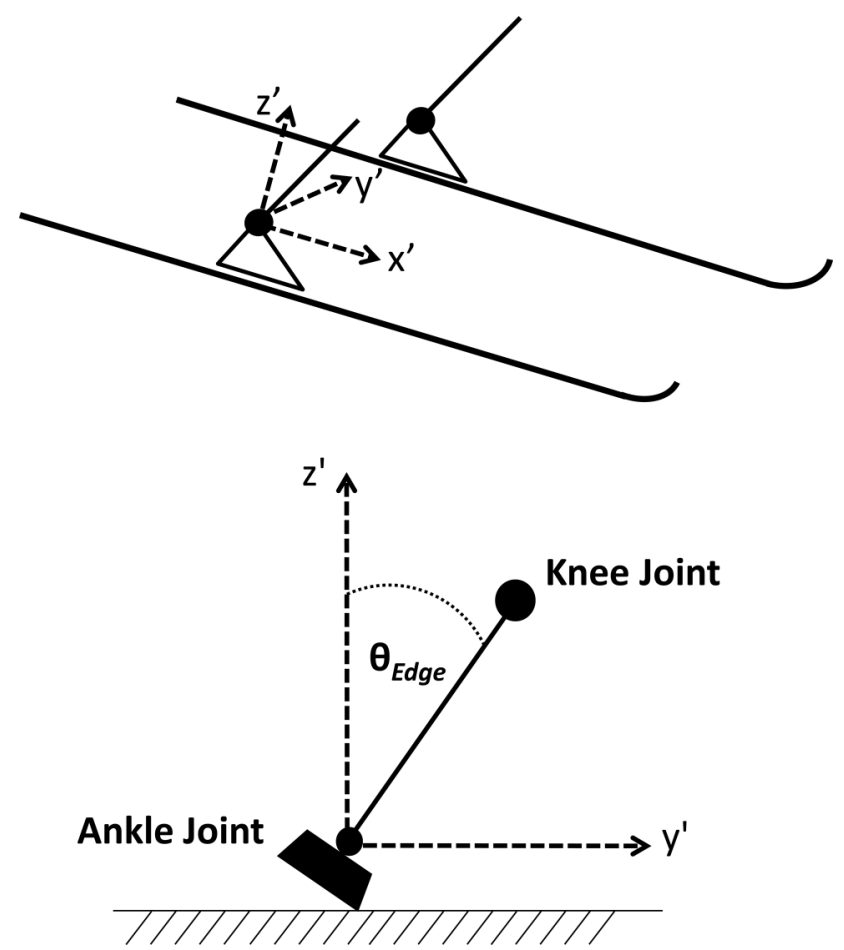

Figure 2 Edge angle ( $\theta_{\text {Edge }}$ ) definition using a local coordinate system at the ankle joint of the outside ski.

correction for pairwise comparison. Provided that the average $\mathrm{F}_{\text {calcGRF }}$ differences were significant within a specific turn phase, this phase was further subdivided into a first and a second half and again was analysed by one-way repeated measures ANOVAs. (3) For the turn phases in which significant average $F_{\text {calcGRF }}$ differences were observed, the importance of the differences in $\mathrm{R}_{\mathrm{COM}}$ and $\mathrm{v}_{\mathrm{COM}}$ to explain the differences in $F_{\text {calcGRF }}$ was assessed by comparing the $\beta$ weights of a multiple regression analysis. (4) For the turn phase with the lowest amount of skidding (ie, the smallest interference of the ski's self-steering effect), a repeated measures multivariate analysis of variance (dependent: $\mathrm{R}_{\mathrm{Ski}}, \theta_{\mathrm{Edge}}, \mathrm{d}_{\mathrm{Fore} / \mathrm{Aft}}, \gamma_{\mathrm{Ski}}$; independent: $30 \mathrm{~m}$ ski, $35 \mathrm{~m}$ ski, $40 \mathrm{~m}$ ski) was calculated. In case of global significance, one-way repeated measures ANOVAs (including post hoc testing with Bonferroni correction) were performed.

\section{RESULTS}

\section{Variables' turn cycle progression}

The group mean curves of $\mathrm{F}_{\text {calcGRF, }} \mathrm{v}_{\mathrm{COM}}$ and $\mathrm{R}_{\mathrm{COM}}$ for the three different pairs of skis are illustrated in figure 3. Those of $\mathrm{R}_{\text {Ski }}, \theta_{\text {Edge }}, \mathrm{d}_{\text {Fore/Aft }}, \gamma_{\text {Ski }}$ are presented in figure 4 .

\section{Differences in ground reaction force}

The descriptive and inferential statistics of average $F_{\text {calcGRF }}$ are presented in table 1 . While there were no significant differences in $F_{\text {calcGRF }}$ overall turn cycle averages between the different pairs of skis, significant differences in $F_{\text {calcGRF }}$ were found for COM Direction Change II. When skiing on the $40 \mathrm{~m}$ skis, the pairwise comparison between the $30 \mathrm{~m}$ and $40 \mathrm{~m}$ skis showed a $\mathrm{F}_{\text {calcGRF }}$ reduction of $7 \%$, and the pairwise comparison between the $35 \mathrm{~m}$ and $40 \mathrm{~m}$ skis showed a $\mathrm{F}_{\text {calcGRF }}$ reduction of $5.9 \%$. Considering only the second half of COM Direction Change II, these differences were even larger $(30 \mathrm{~m} / 40 \mathrm{~m}:-10.9 \% ; 35 \mathrm{~m} /$ $40 \mathrm{~m}:-7.2 \%)$.
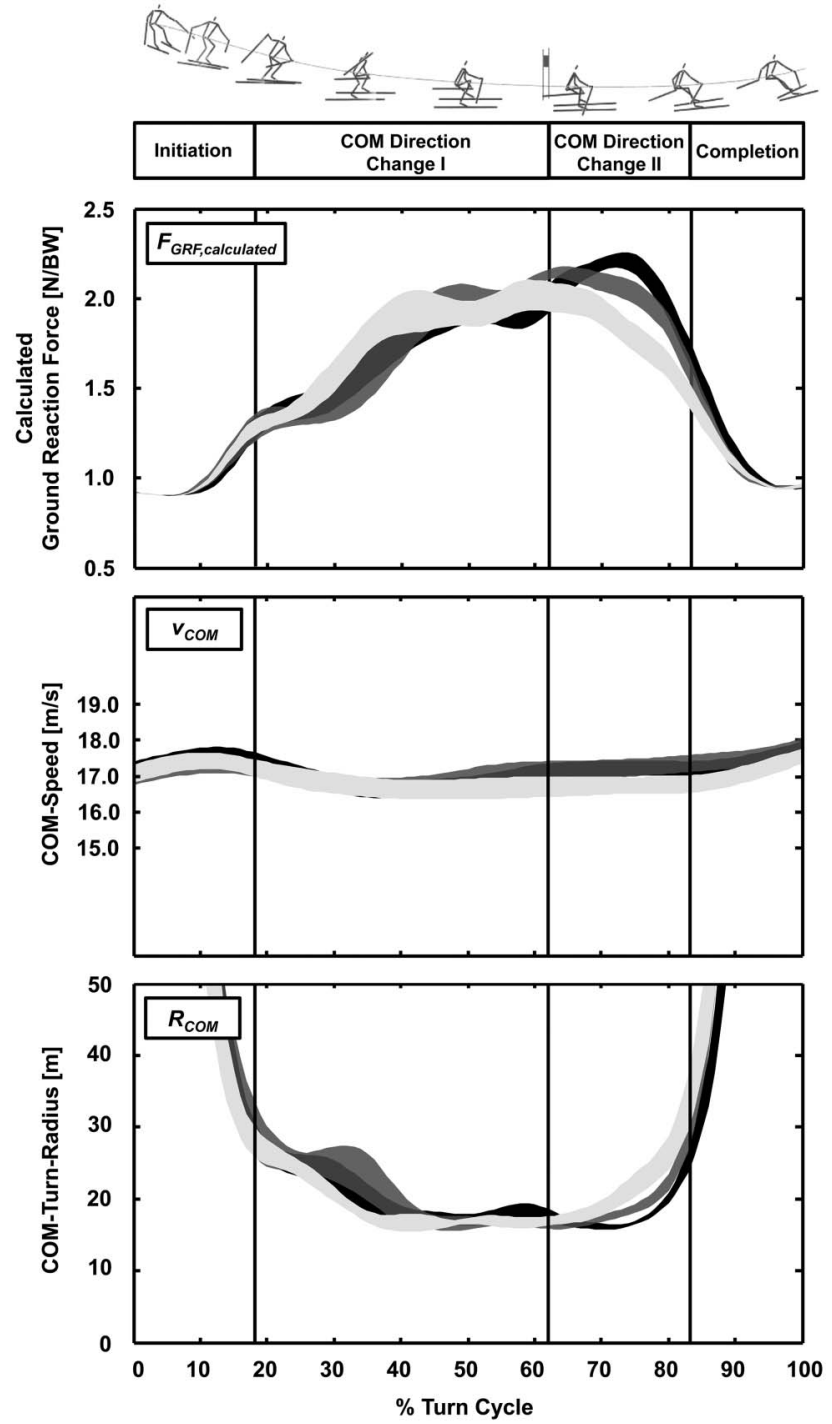

Figure 3 Areas of uncertainty around the estimate of the mean $( \pm S E)$ illustrating calculated ground reaction force $\left(\mathrm{F}_{\text {calcGRF }}\right)$ and the $\mathrm{F}_{\text {calcGRF }}$ predicting variables COM speed ( $\left.\mathrm{v}_{\mathrm{COM}}\right)$ and COM turn radius $\left(\mathrm{R}_{\mathrm{COM}}\right)$ over one turn cycle; black: $30 \mathrm{~m}$ ski; dark grey (transparent): $35 \mathrm{~m}$ ski; light grey: $40 \mathrm{~m}$ ski. COM, centre of mass.

\section{Contribution of COM turn radius and COM speed to ground reaction force}

The results of the multiple regression analysis assessing the importance of the differences in $\mathrm{R}_{\mathrm{COM}}$ and $\mathrm{v}_{\mathrm{COM}}$ to explain the differences in $\mathrm{F}_{\text {calcGRF }}$ during the second half of the COM Direction Change II are presented in table 2. For both the $30 \mathrm{~m} /$ $40 \mathrm{~m}$ ski comparison and the $35 \mathrm{~m} / 40 \mathrm{~m}$ ski comparison, the $\mathrm{R}_{\mathrm{COM}}$ differences were of greater importance for explaining the $\mathrm{F}_{\text {calcGRF }}$ differences than the $\mathrm{v}_{\mathrm{COM}}$ differences. Additional analysis revealed that $\mathrm{R}_{\mathrm{COM}}$ significantly differed between the $30 \mathrm{~m}$ and the $40 \mathrm{~m}$ skis, as well as between the $35 \mathrm{~m}$ and $40 \mathrm{~m}$ skis $(\mathrm{p}<0.05)$.

\section{Differences in ski turn radius and skiers' actions}

The descriptive and inferential statistics of average $\mathrm{R}_{\text {Ski }}, \theta_{\text {Edge }}$, $\mathrm{d}_{\text {Fore/Aft }}$ and $\gamma_{\text {Ski }}$ during COM Direction Change II are presented in table 3. While there were no significant differences in the variables related to the skiers actions $\left(\theta_{\mathrm{Edge}}, \mathrm{d}_{\mathrm{Fore} / \mathrm{Aft}}\right.$ and $\left.\gamma_{\mathrm{Ski}}\right)$ between the different pairs of skis, significant differences in $\mathrm{R}_{\mathrm{Ski}}$ COM Direction Change II phase averages were found. The 

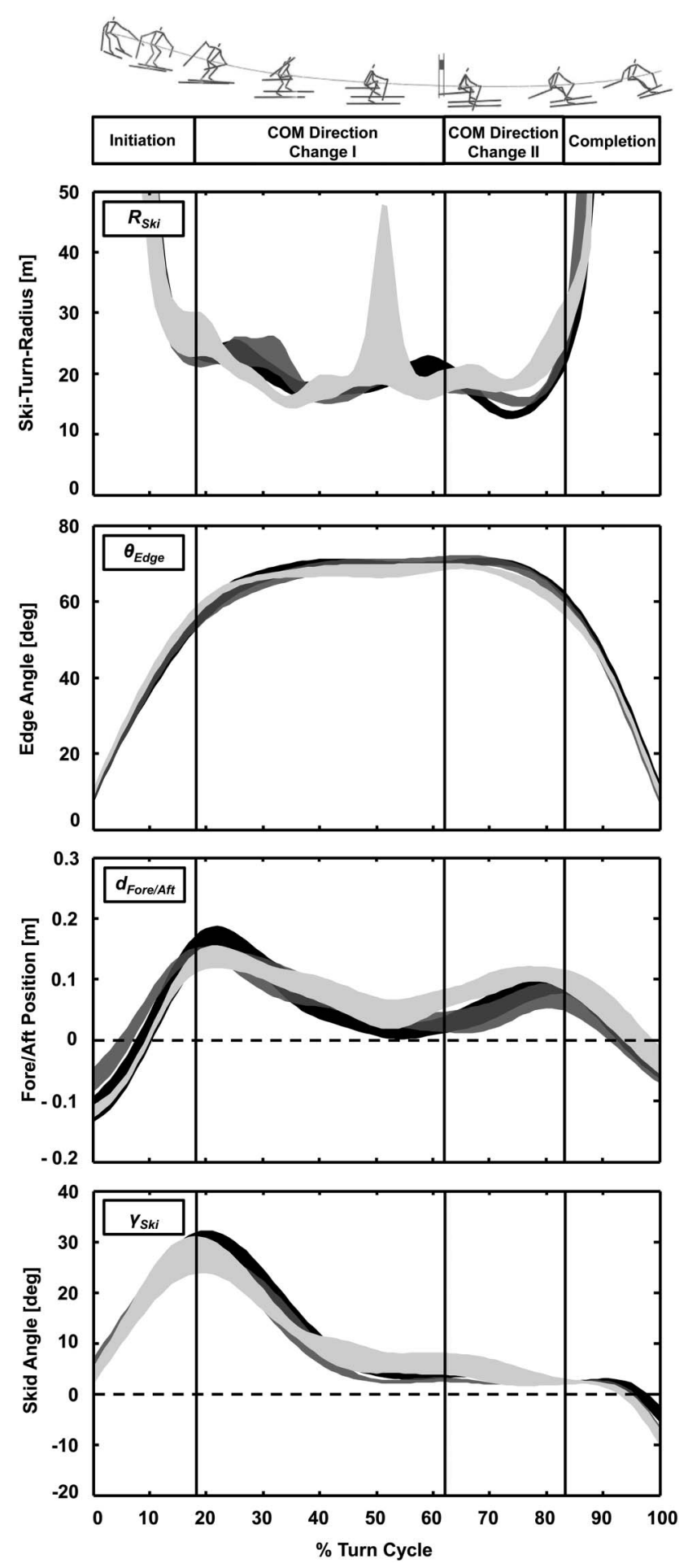

Figure 4 Areas of uncertainty around the estimate of the mean $( \pm \mathrm{SE})$ illustrating the variables ski turn radius $\left(\mathrm{R}_{\mathrm{ski}}\right)$, edge angle $\left(\theta_{\mathrm{Edge}}\right)$, fore/ aft position ( $\left.d_{\text {Fore/Aft }}\right)$ and skid angle $\left(\gamma_{\text {Ski }}\right)$ over one turn cycle; black: 30 m ski; dark grey (transparent): 35 m ski; light grey: 40 m ski.

pairwise comparison between the $30 \mathrm{~m}$ and $40 \mathrm{~m}$ skis showed a $\mathrm{R}_{\mathrm{Ski}}$ increase of $14.3 \%$, and the pairwise comparison between the $35 \mathrm{~m}$ and $40 \mathrm{~m}$ skis showed a $\mathrm{R}_{\text {Ski }}$ increase of $11.9 \%$ when skiing on the $40 \mathrm{~m}$ skis.

\section{DISCUSSION}

The main findings of this study were: (1) between the $30 \mathrm{~m}$ and $35 \mathrm{~m}$ ski, no significant differences in $\mathrm{F}_{\text {calcGRF }}$ were found; (2) during COM Direction Change II, and particularly during the second half of this turn phase, the $30 \mathrm{~m} / 40 \mathrm{~m}$ and $35 \mathrm{~m} / 40 \mathrm{~m}$ pairwise comparisons indicated significantly lower $F_{\text {calcGRF }}$ averages when skiing on the $40 \mathrm{~m}$ ski $(30 \mathrm{~m} / 40 \mathrm{~m}$ : $-10.9 \%$; $35 \mathrm{~m} / 40 \mathrm{~m}$ : $-7.2 \%$ ); (3) $\mathrm{R}_{\mathrm{COM}}$ differences were of greater importance for providing an explanation for these $F_{\text {calcGRF }}$ differences than the differences in $\mathrm{v}_{\mathrm{COM}}$; (4) During the turn phase with the lowest amount of skidding (ie, the smallest interference of the ski's self-steering effect), significant differences were found in $R_{\text {Ski }}(30 \mathrm{~m} / 40 \mathrm{~m}$ : $+14.3 \% ; 35 \mathrm{~m} / 40 \mathrm{~m}$ : $+11.9 \%)$, but no differences in $\theta_{\text {Edge }}, \mathrm{d}_{\text {Fore/Aft }}$ and $\gamma_{\text {Ski }}$ were observed.

\section{Methodological considerations}

Prior to interpreting the study's findings, it has to be pointed out that the current study design only allows for the derivation of first clues about the effect of sidecut radius on injury risk. Although these clues must be verified by epidemiological studies before the effectiveness of the investigated prevention measures can be judged as conclusive, they are, nevertheless, at this early stage of gathering knowledge, an important means of developing strategies to protect the athletes' health.

At a first glance, a limitation of the current study might be the fact that only six participants and only one representative turn for each ski intervention were considered for the statistical analysis. This choice has cons and pros: On the one hand, it will result in a certain loss of variability information which limits the unrestricted generalisability of the study findings. On the other hand, only a limited number of trials can guarantee a high validity of the outcome measures, because the span of time with constant environmental conditions in field is limited (eg, changing snow conditions as a result of performing repetitive runs on the same course). Furthermore, to provide sufficient accuracy for measuring the underlying COM kinematics in field, the 'videobased 3D kinematics' method was an indispensable choice. Despite major advantages in measurement accuracy, this method has substantial limitations with regard to the capture volume and the 3D reconstruction efforts (manual digitising). Thus, based on these considerations, the measurement protocol of the current study can be argued to be appropriate.

\section{The effect of sidecut radius on the mechanics of turning}

Based on the most common theoretical models, greater sidecut radius is expected to increase the resulting ski turn radius, ${ }^{12} 13$ and, therefore, also is expected to decrease the acting ground acting reaction forces, ${ }^{10} 11$ provided that the performed edge angle is the same. This was only partially observed in the current study.

Despite almost identical edge angles, $F_{\text {calcGRF }}$ and $R_{\text {Ski }}$ did not differ between the skis varying in sidecut radius over a wide range of the turn (Initiation, COM Direction Change I and Completion phase). This might be explained by the fact that the aforementioned theoretical models assume the occurrence of a purely carved turn without any skidding. However, in a real skiing situation, athletes adjust the amount of skidding, particularly during the aforementioned turn phases (figure 4).

After gate passage (during COM Direction Change II), the theoretical expectation that a greater sidecut radius increases the resulting ski turn radius coincided with the experimental findings. This might be explained by the generally higher amount of carving (ie, lower amount of skidding) during this phase (figure 4), which is a major assumption underlying the aforementioned theoretical models. Furthermore, based on the current study findings, it seems plausible that after gate passage, $\mathrm{R}_{\text {Ski }}$ differed mainly because of the changed sidecut radius of 
Table 1 Descriptive and inferential statistics of average of calculated ground reaction force $\left(F_{\text {calcGRF }}\right)$ between the tested skis ( $30 \mathrm{~m}, 35 \mathrm{~m}, 40 \mathrm{~m}$ sidecut radius) for: (Turn) turn average; ${ }^{\text {(Initiation) }}$ average of the Initiation phase; (COM DC I) average of the COM Direction Change I phase; (COM DC II) average of the COM Direction Change // phase; (Completion) ${ }^{\text {average of the Completion phase; (first) }}$ and ${ }^{\text {(second) }}$ indicate the first and the second half of a specific turn phase, respectively

\begin{tabular}{|c|c|c|c|c|c|c|c|c|c|}
\hline \multirow[b]{2}{*}{ Parameter } & \multirow[b]{2}{*}{ Subparameter } & \multicolumn{3}{|l|}{ Mean \pm SD } & \multicolumn{2}{|l|}{ ANOVA } & \multicolumn{3}{|c|}{ Pairwise comparisons } \\
\hline & & $30 \mathrm{~m}$ & $35 \mathrm{~m}$ & $40 m$ & $\mathrm{p}$ Value & eta $a_{p}^{2}$ & $30 \mathrm{~m} / 35 \mathrm{~m}$ & $30 \mathrm{~m} / 40 \mathrm{~m}$ & $35 \mathrm{~m} / 40 \mathrm{~m}$ \\
\hline \multicolumn{10}{|l|}{ Turn cycle } \\
\hline $\mathrm{F}_{\text {calcGRF }}{ }^{\text {(Turn) }}(\mathrm{N} / \mathrm{BW})$ & & $1.56 \pm 0.07$ & $1.55 \pm 0.06$ & $1.52 \pm 0.07$ & 0.227 & 0.232 & & & \\
\hline \multicolumn{10}{|l|}{ Turn phase } \\
\hline $\mathrm{F}_{\text {calcGRF }}{ }^{\text {(Initiation) }}$ (N/BW) & & $0.97 \pm 0.03$ & $0.96 \pm 0.02$ & $0.98 \pm 0.04$ & 0.454 & 0.140 & & & \\
\hline $\mathrm{F}_{\text {calcGRF }}($ COM DC I) $(\mathrm{N} / \mathrm{BW})$ & & $1.75 \pm 0.11$ & $1.74 \pm 0.19$ & $1.75 \pm 0.18$ & 0.996 & 0.001 & & & \\
\hline $\mathrm{F}_{\text {calcGRF }}{ }^{(\text {COM DC II) }}(\mathrm{N} / \mathrm{BW})$ & & $2.05 \pm 0.12$ & $2.02 \pm 0.10$ & $1.91 \pm 0.15$ & $0.005^{* *}$ & 0.698 & & $-7 \% *$ & $-5.9 \% *$ \\
\hline & $\mathrm{F}_{\text {calcGRF }}($ COM DC II, first) (N/BW) & $2.09 \pm 0.14$ & $2.11 \pm 0.09$ & $2.01 \pm 0.19$ & 0.259 & 0.240 & & & \\
\hline & $\mathrm{F}_{\text {calcGRF }}{ }^{(\mathrm{COM} D C \mathrm{II} \text {, second) }}(\mathrm{N} / \mathrm{BW})$ & $1.97 \pm 0.17$ & $1.89 \pm 0.13$ & $1.75 \pm 0.11$ & $0.015^{*}$ & 0.651 & & $-10.9 \% *$ & $-7.2 \% *$ \\
\hline $\mathrm{F}_{\text {calcGRF }}{ }^{\text {(Completion) }}$ (N/BW) & & $1.15 \pm 0.03$ & $1.13 \pm 0.02$ & $1.12 \pm 0.02$ & 0.123 & 0.350 & & & \\
\hline
\end{tabular}

Repeated measure ANOVA results are based on the Greenhouse-Geisser correction. Post hoc method with Bonferroni correction for pairwise comparison. Level of significance: ${ }^{*} p<0.05,{ }^{* *} p<0.01,{ }^{* * *} p<0.001$.

ANOVA, analysis of variance; BW, body weight; COM, centre of mass.

the ski and not due to altered skiers' actions (no differences in $\theta_{\text {Edge }}, d_{\text {Fore/Aft }}$ and $\gamma_{\text {Ski }}$ were observed).

As found in this study, $\mathrm{R}_{\mathrm{COM}}$ and $\mathrm{v}_{\mathrm{COM}}$ explained more than $97 \%$ of the variance in the reported $\mathrm{F}_{\text {calcGRF }}$ differences between the tested pairs of skis. This is in line with previous findings by Gilgien et al, ${ }^{34}$ who demonstrated that, in contrast to other disciplines, in GS centripetal acceleration $\left(\mathrm{v}_{\mathrm{COM}}^{2} / \mathrm{R}_{\mathrm{COM}}\right)$

Table 2 Results of the multiple regression analysis assessing the importance of the $30 \mathrm{~m} / 40 \mathrm{~m}$ ski difference and $35 \mathrm{~m} / 40 \mathrm{~m}$ ski difference in COM speed ( $\left.\mathrm{v}_{\text {COM }}\right)$ and COM turn radius $\left(\mathrm{R}_{\mathrm{COM}}\right)$ to explain the corresponding difference in the dependent variable calculated ground reaction force $\left(\mathrm{F}_{\text {calcGRF }}\right)$ during the second half of the COM Direction Change II phase (COM DC II, second)

\begin{tabular}{|c|c|c|}
\hline Predictors of FcalcGRF differences & 及-weight & $\mathrm{p}$ Value \\
\hline \multicolumn{3}{|l|}{30 m/40 m ski difference (Model ${ }^{\star}$ ) } \\
\hline$R_{\text {COM }}$ (COM DC II, second) $(30 \mathrm{~m} / 40 \mathrm{~m})$ & -0.865 & 0.002 \\
\hline $\mathrm{V}_{\text {COM }}($ (COM DC II, second) $(30 \mathrm{~m} / 40 \mathrm{~m})$ & 0.371 & 0.018 \\
\hline \multicolumn{3}{|l|}{35 m/40 m ski difference (Modelt) } \\
\hline$R_{\text {COM }}$ (COM DC II, second) $(35 \mathrm{~m} / 40 \mathrm{~m})$ & -0.687 & 0.002 \\
\hline $\mathrm{V}_{\text {COM }}($ (COM DC II, second) $(35 \mathrm{~m} / 40 \mathrm{~m})$ & 0.581 & 0.003 \\
\hline
\end{tabular}

is the main contributor to the ground reaction force. Despite the fact that by physical laws $\mathrm{v}_{\mathrm{COM}}$ contributes in square to centripetal force (radial component of $\mathrm{F}_{\text {calcGRF}}$ ), its importance for providing an explanation for the differences in $F_{\text {calcGRF }}$ is lower than that of the $\mathrm{R}_{\mathrm{COM}}$ differences.

The role of sidecut radius in the context of injury prevention Based on the results of the current study, one preventative benefit of skis with greater sidecut radius might be found in the sidecut-induced (ie, not skiers' action-induced) reduction of $\mathrm{F}_{\text {calcGRF }}$ and increase of $\mathrm{R}_{\text {Ski }}$. This can be considered to be an indirect indication for a reduced self-steering effect of the skis, which is known to play a central role within ACL injury mechanisms in alpine ski racing. ${ }^{5}$ In other words: in the case of an uncontrolled skiing situation (eg, a sudden catch of the edge while recovering from an out-of-balance situation), skis with greater sidecut are expected to be less likely to carve sharply inward and to force the knee into excessive adverse valgus and internal rotation.

Another preventative gain of increasing the sidecut radius of the skis might be found in the assertion that within the competition discipline GS, injury risk is most likely associated with high loads while turning, ${ }^{34}$ and that the skier's balance might be challenged by a combined occurrence of small turn radii and high loads. ${ }^{30}$ In this context, the current study found that greater sidecut radius significantly reduces $\mathrm{F}_{\text {calcGRF }}$ by up to $7 \%$

Table 3 Descriptive and inferential statistics of average ski turn radius $\left(\mathrm{R}_{\text {ski }}\right)$, edge angle $\left(\theta_{\text {Edge }}\right)$, fore/aft position $\left(\mathrm{d}_{\text {Fore/Aft }}\right)$ and skid angle $\left(\gamma_{\text {ski }}\right)$

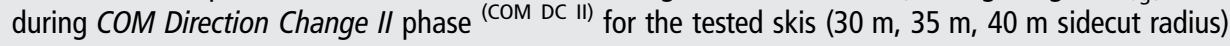

\begin{tabular}{|c|c|c|c|c|c|c|c|c|}
\hline & \multicolumn{3}{|l|}{ Mean \pm SD } & \multicolumn{2}{|l|}{ ANOVAt } & \multicolumn{3}{|c|}{ Pairwise comparisons } \\
\hline & $30 \mathrm{~m}$ & $35 \mathrm{~m}$ & $40 \mathrm{~m}$ & p Value & eta $a_{p}^{2}$ & $30 \mathrm{~m} / 35 \mathrm{~m}$ & $30 \mathrm{~m} / 40 \mathrm{~m}$ & $35 \mathrm{~m} / 40 \mathrm{~m}$ \\
\hline $\mathrm{R}_{\mathrm{Ski}}{ }^{(\mathrm{COM} D C \mathrm{II})}(\mathrm{m})$ & $16.70 \pm 1.43$ & $17.06 \pm 1.60$ & $19.08 \pm 1.23$ & $0.012^{*}$ & 0.715 & & $+14.3 \%$ * & $+11.9 \%$ *** \\
\hline$\theta_{\text {Edge }}{ }^{\text {(COM DC II) }}$ (degree) & $68.6 \pm 2.3$ & $68.8 \pm 3.1$ & $67.2 \pm 1.6$ & 0.201 & 0.290 & & & \\
\hline $\mathrm{d}_{\text {Fore/Aft }}($ COM DC II) $(\mathrm{m})$ & $0.06 \pm 0.05$ & $0.05 \pm 0.06$ & $0.08 \pm 0.03$ & 0.471 & 0.133 & & & \\
\hline$\gamma_{\text {Ski }}{ }^{(\text {COM DC II) }}$ (degree) & $3.0 \pm 0.7$ & $2.0 \pm 0.4$ & $3.7 \pm 3.6$ & 0.390 & 0.153 & & & \\
\hline
\end{tabular}

Repeated measure ANOVA results are based on the Greenhouse-Geisser correction. Post hoc method with Bonferroni correction for pairwise comparison. Level of significance: ${ }^{*} p<0.05,{ }^{* *} p<0.01,{ }^{* * *} p<0.001$.

tPrior the ANOVA test a global significance was identified (MANOVA: $p<0.008$, eta $a_{p}^{2}=0.712$ ).

ANOVA, analysis of variance; COM, centre of mass; MANOVA, multivariate analysis of variance. 
and significantly increases $\mathrm{R}_{\mathrm{Ski}}$ by up to $14.3 \%$ during $C O M$ Direction Change II. This turn phase is of particular interest, because more than half of the ACL injuries occur while turning, mainly during the steering phase out of the fall line after gate passage, ${ }^{5}$ which corresponds to the COM Direction Change II phase in the current study. During this phase, $\mathrm{R}_{\text {Ski }}$ reaches its minimum, and $F_{\text {calcGRF }}$ is already at a very high magnitude, close to the athlete's physical limit (up to $2.3 \mathrm{~N} /$ body weight, figure 2), which might conceivably increase the risk for out-of-balance situations.

On a final note, however, it has to be pointed out that based on the results of this study, only a substantial increase in sidecut radius might lead to this preventative gain and that the effectiveness of the investigated prevention measures must be verified by epidemiological studies before the aforementioned interpretations can be judged as conclusive.

\section{CONCLUSION}

This biomechanical field study demonstrated that within the competition discipline GS, substantially greater sidecut radius decreases ground reaction force and increases ski turn radius while steering out of the fall line after gate passage. Since no corresponding differences in the skiers' actions (edging, fore/aft leaning and skidding) were found, the aforementioned differences are most likely attributable to altered sidecut radii only. This can be considered to be an indirect indication for a reduced self-steering effect, which is known to play a central role within ACL injury mechanisms in alpine ski racing. Thus, skis with substantially greater sidecut might help to improve the athletes' safety in alpine ski racing.

\section{What are the findings?}

- Within the competition discipline giant slalom, greater sidecut radius leads to a substantial decrease in ground reaction force while steering out of the fall line after gate passage.

- This significant decrease in ground reaction force can be principally explained by a significant increase in centre of mass turn radius, and only partially explained by altered centre of mass speed.

\section{How might it impact on clinical practice in the future?}

- Greater sidecut radius of giant slalom skis might prevent anterior cruciate ligament $(A C L)$ injuries in alpine ski racing: the sidecut-induced increase in ski turn radius observed in the current study provides indirect evidence of a less self-steering of the ski. Self-steering plays a central role in the mechanisms of $\mathrm{ACL}$ injuries.

- However, this preliminary evidence to protect the athletes' health must be verified by epidemiological studies before their effectiveness can be judged.

Contributors JS, JK and EM conceptualised the study design. JS organised and coordinated the biomechanical field study. JS, JK, MG contributed to the data collection. JS conducted the data processing and analysis. All authors contributed to the intellectual content of the study, manuscript writing and approved the final version of this article.
Funding This study was financially supported by the International Ski Federation (FIS) Injury Surveillance System (ISS). The funding source had no involvement in the study design; in the collection, analysis and interpretation of data; in the writing of the report; or in the decision to submit this paper for publication.

Competing interests None declared.

Ethics approval This study was approved by the Ethics Committee of the Department of Sport Science and Kinesiology at the University of Salzburg.

Provenance and peer review Not commissioned; externally peer reviewed.

Open Access This is an Open Access article distributed in accordance with the Creative Commons Attribution Non Commercial (CC BY-NC 4.0) license, which permits others to distribute, remix, adapt, build upon this work non-commercially, and license their derivative works on different terms, provided the original work is properly cited and the use is non-commercial. See: http://creativecommons.org/ licenses/by-nc/4.0/

\section{REFERENCES}

1 Pujol N, Blanchi MP, Chambat P. The incidence of anterior cruciate ligament injuries among competitive alpine skiers: a 25-year investigation. Am J Sports Med 2007;35:1070-4.

2 Florenes TW, Bere T, Nordsletten L, et al. Injuries among male and female World Cup alpine skiers. Br J Sports Med 2009;43:973-8.

3 Bere T, Flørenes TW, Nordsletten $L$, et al. Sex differences in the risk of injury in World Cup alpine skiers: a 6-year cohort study. Br J Sports Med 2014;48: 36-40.

4 Westin M, Alricsson M, Werner S. Injury profile of competitive alpine skiers: a five-year cohort study. Knee Surg Sports Traumatol Arthrosc 2012;20: $1175-81$.

5 Bere T, Flørenes TW, Krosshaug T, et al. Mechanisms of anterior cruciate ligament injury in World Cup alpine skiing: a systematic video analysis of 20 cases. Am J Sports Med 2011;39:1421-9.

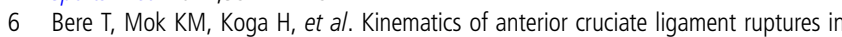
World Cup alpine skiing: 2 case reports of the slip-catch mechanism. Am J Sports Med 2013;41:1067-73.

7 Spörri J, Kröll J, Amesberger G, et al. Perceived key injury risk factors in world cup alpine ski racing-an explorative qualitative study with expert stakeholders. $\mathrm{Br} J$ Sports Med 2012;46:1059-64.

8 LeMaster R. Ultimate skiing. Leeds, UK: Human Kinetics, 2009.

9 Müller $\mathrm{E}$, Schwameder $\mathrm{H}$. Biomechanical aspects of new techniques in alpine skiing and ski-jumping. J Sports Sci 2003;21:679-92.

10 Niessen W, Müller E. Carving-biomechanische Aspekte bei der Verwendung stark taillierter Skier und erhöhter Standflächen im alpinen Skisport. Leistungssport 1999;1:39-44.

11 Mössner M, Nachbauer W, Schindelwig K. Einfluss der Skitaillierung auf Schwungradius und Belastung. Sportverl Sportschad 1997;11:140-5.

12 Howe J. The new skiing mechanics. 2nd edn. Waterford: McIntire Publishing, 2001.

13 Jentschura UD, Fahrbach F. Physics of skiing: the ideal-carving equation and its applications. Can J Phys 2004;82:249-61.

14 Federolf $P$, Roos $M$, Lüthi $A$, et al. Finite element simulation of the ski-snow interaction of an alpine ski in a carved turn. Sports Eng 2010;12:123-33.

15 Federolf $P$, JeanRichard $F$, Fauve $M$, et al. Deformation of snow during a carved ski turn. Cold Regions Sci Technol 2006;46:69-77.

16 Sahashi T, Ichino S. Carving-turn and edging angle of skis. Sports Eng 2001:4:135-45.

17 Mössner M, Heinrich D, Schindelwig K, et al. Modeling the ski-snow contact in skiing turns using a hypoplastic vs an elastic force-penetration relation. Scand J Med Sci Sports 2014;24:577-85.

18 Renshaw A, Mote C. A model for the turning snow ski. In: Mote C, Johnson R, eds. Skiing trauma and safety. American Society for Testing and Materials, Philadelphia, 1991:217-38.

19 Heinrich D, Mössner M, Kaps $P$, et al. Influence of ski bending stiffness on the turning radius of alpine skis at different edging angles and velocities. In: Moritz $E_{\text {, }}$ Haake S, eds. Engineering of sport 6. Munich, 2006:207-12.

20 Mössner $M$, Heinrich $D$, Kaps $P$, et al. Computer simulation of consecutive ski turns. J ASTM Int 2008;5:126-36.

21 Mössner $M$, Heinrich $D$, Kaps $P$, et al. Effects of ski stiffness in a sequence of ski turns. In: Müller E, Lindinger S, Stöggl T, eds. Science and skiing IV. Maidenhead: Meyer \& Meyer Sport (UK) Ltd, 2009:374-88.

22 Heinrich $D$, Mössner M, Kaps $P$, et al. Calculation of the contact pressure between ski and snow during a carved turn in Alpine skiing. Scand J Med Sci Sports 2010;20:485-92

23 FIS. Specification for competition equipment and comercial markings. Edition 2012/ 2013 ed. Oberhofen, Switzerland: Self-publisher, 2012.

24 Drenk V, ed. Photogrammetric evaluation procedures for pannable and tiltable cameras of varlable focal length. Conference Proceedings ISBS -12 International Symposium on Biomechanics in Sports; Budapest, 1994:27-30. 
25 Klous M, Müller E, Schwameder H. Collecting kinematic data on a ski/snowboard track with panning, tilting, and zooming cameras: is there sufficient accuracy for a biomechanical analysis? J Sports Sci 2010;28:1345-53.

26 Jackson KM. Fitting of mathematical functions to biomechanical data. IEEE Trans Biomed Eng 1979;26:122-4.

27 Smith G. An iterative segment length normalization routine for use with linked segment models. In: Gregor RJ, Litsky AS, eds. Conference Proceedings of the18th Annual Meeting of the American Society of Biomechanics; Columbus, $\mathrm{OH}$, 1994:35-6.

28 de Leva P. Joint center longitudinal positions computed from a selected subset of Chandler's data. J Biomech 1996;29:1231-3.

29 Clauser CE, Mc Conville JT, Young JW. Weight, volume and centre of mass segments of the human body. AMRL TR69-70. OH: Wright-Patterson Airforce Base, 1969.
30 Spörri J, Kröll J, Schwameder $\mathrm{H}$, et al. Course setting and selected biomechanical variables related to injury risk in alpine ski racing: an explorative case study. $\mathrm{Br}$ J Sports Med 2012;46:1072-7.

31 Spörri J, Kröll J, Schwameder $\mathrm{H}$, et al. Turn characteristics of a top world class athlete in giant slalom —a case study assessing current performance prediction concepts. Int J Sport Sci Coach 2012;7:647-59.

32 Supej M, Kugovnik O, Nemec B. Kinematic determination of the beginning of a ski turn. Kinesiologia Slovenica 2003:9:11-17.

33 Gilgien M, Spörri J, Chardonnens J, et al. Determination of external forces in alpine skiing using a differential global navigation satellite system. Sensors (Basel) 2013;13:9821-35.

34 Gilgien M, Spörri J, Kröll J, et al. Mechanics of turning and jumping and skier speed are associated with injury risk in men's world cup alpine skiing: a comparison between the competition disciplines. Br J Sports Med 2014;48:742-7. 